\title{
Large-scale survey to describe acne management in Brazilian clinical practice
}

This article was published in the following Dove Press journal:

Clinical, Cosmetic and Investigational Dermatology

9 November 2015

Number of times this article has been viewed

\section{Sophie Seitél \\ Clarice Caixeta ${ }^{2}$ \\ Loan Towersey ${ }^{3}$}

'La Roche-Posay Dermatological Laboratories, Asnières, France;

${ }^{2}$ La Roche-Posay Dermatological Laboratories, Rio de Janeiro, RJ, Brazil; ${ }^{3}$ AIDS Division, Hospital Municipal Carlos Tortelly, Niterói, RJ, Brazil
Correspondence: Sophie Seité La Roche-Posay Dermatological Laboratories, II 0 Avenue Henri Barbusse, 92602 Asnières Cedex, France Tel +33 I 46886544

Fax +33 | 46882922

Email sophie.seite@loreal.com
Background: Acne is a chronic disease of the pilosebaceous unit that mainly affects adolescents. It is the most common dermatological problem, affecting approximately $80 \%$ of teenagers between 12 and 18 years of age. Diagnosis is clinical and is based on the patient's age at the time the lesions first appear, and on its polymorphism, type of lesions, and their anatomical location. The right treatment for the right patient is key to treating acne safely. The aim of this investigational survey was to evaluate how Brazilian dermatologists in private practice currently manage acne.

Materials and methods: Dermatologists practicing in 12 states of Brazil were asked how they manage patients with grades I, II, III, and IV acne. Each dermatologist completed a written questionnaire about patient characteristics, acne severity, and the therapy they usually prescribe for each situation.

Results: In total, 596 dermatologists were interviewed. Adolescents presented as the most common acneic population received by dermatologists, and the most common acne grade was grade II. The doctors could choose more than one type of treatment for each patient, and treatment choices varied according to acne severity. A great majority of dermatologists considered treatment with drugs as the first alternative for all acne grades, choosing either topical or oral presentation depending on the pathology severity. Dermocosmetics were chosen mostly as adjunctive therapy, and their inclusion in the treatment regimen decreased as acne grades increased.

Conclusion: This survey illustrates that Brazilian dermatologists employ complex treatment regimens to manage acne, choosing systemic drugs, particularly isotretinoin, even in some cases of grade I acne, and heavily prescribe antibiotics. Because complex regimens are harder for patients to comply with, this result notably raises the question of adherence, which is a key factor in successful treatment.

Keywords: acne, management, severity of acne, Brazil

\section{Introduction}

Acne is a chronic disease of the pilosebaceous unit that affects mainly adolescents. It is the most common dermatological disease, affecting approximately $80 \%$ of teenagers between 12 and 18 years of age. It is predominant in female adolescents, where it first appears around 14 years of age, and is less severe than in males who start showing symptoms at approximately 16 years of age. ${ }^{1}$ Acne is the most common diagnosis made by dermatologists but is also commonly made by physicians other than dermatologists. Diagnosis is confirmed by clinical observation, and is based on the patient's age at the time that the lesions first appear, and the type of polymorphism, lesions, and their location. ${ }^{2,3}$

The pathogenesis and existing treatment strategies for acne are complex. Moreover, acne interferes with quality of life and requires both therapeutic and 
psychological support. ${ }^{4,5}$ Studies suggest that the emotional impact of acne is comparable to that experienced by patients with systemic diseases, such as diabetes and epilepsy. ${ }^{6,7}$ The right treatment for the right patient is key to treating acne safely. Numerous published guidelines, recommendations, and scientific reviews on therapeutic management of acne exist today. The Global Alliance to Improve Outcomes in Acne published an algorithm for acne management in 2003, and updated it in 2009:1,8,9 in the same year, Brazilian dermatologists Ramos-e-Silva and Carneiro published an article with recommendations for treating different types of acne severity. ${ }^{1}$ Additionally, although not yet included in the treatment algorithms, dermocosmetic products are often prescribed as part of acne treatment regimens. ${ }^{10}$ Despite acne treatment guidelines being regularly communicated and updated, it is not known if dermatologists actually follow the recommendations in private practice. It is important to investigate the practices that dermatologists adopt to better understand the reality of therapeutic approaches.

In this context, we performed a survey to assess the therapeutic choices made by Brazilian dermatologists for grade I, II, III, and IV acne. For each level of acne severity, we recorded population characteristics, the product prescribed, and whether or not this treatment was associated with dermocosmetic prescription.

\section{Materials and methods}

This survey was conducted between January 2014 and February 2014, with 596 dermatologists in private practice in 12 states of Brazil, including São Paulo, Minas Gerais, Rio de Janeiro, Paraná, Rio Grande do Sul, Espírito Santo, Santa Catarina, Distrito Federal, Goiás, Rio Grande do Norte, Paraíba, and Amapá participating. Doctors received a questionnaire with six questions concerning the characteristics of the population of acne patients seen in consultation, the most frequent acne grades received (I, II, III, and IV), and doctors' therapeutic choices for each grade. Acne classification was based on the Brazilian Society of Dermatology description: grade I, comedones, without inflammatory lesions; grade II, comedones, papules, and pustules with variable intensity and few to numerous inflammatory lesions with some erythema; grade III, comedones, papules, and pustules with intense inflammatory reactions leading to nodule formation, which may contain pus (cysts); grade IV, comedones, papules, pustules, and larger cystic fistulas forming lesions.

For each severity level, the doctors were asked if they would choose: 1) topical drug treatment (ie, benzoyl peroxide, isotretinoin/tretinoin, erythromycin/clindamycin, azelaic acid, combination benzoyl peroxide plus adapalene, combination benzoyl peroxide plus clindamycin, combination erythromycin plus isotretinoin, combination clindamycin plus tretinoin, and others: salicylic acid, beta-lipohydroxy acid, nicotinamide, sulfur, zinc gluconate, or glycolic acid); 2) systemic drug treatment (ie, isotretinoin or cyclins, [lymecycline, tetracycline, minocycline, doxycycline, or azithromycin/erythromycin], oral contraceptives [ethinyl estradiol plus second and third generation progestogens], or antiandrogens [cyproterone acetate, chlormadinone acetate, dienogest, trimegestone, spironolactone, drospirenone, or flutamide]); or 3) dermocosmetic treatment (associated with drug treatment; either at the same time or in maintenance or in monotherapy).

Data analysis was performed by Insider Inteligência de Mercado for all questionnaires completed by dermatologists. Variables were expressed by percentage (\%); quantitative data were expressed by mean \pm standard deviation (SD; minimum-maximum) and median. As this study corresponded only to doctors interviews, ethical approval was deemed not to apply. Any interventional action was made during this search.

\section{Results}

Regarding the acne patients received by the Brazilian dermatologists questioned, $52 \%$ of dermatologists treated only adolescents (under 18 years of age), $41 \%$ of dermatologists treated both adolescents and adults, and 7\% of dermatologists treated only adults. Most of the adult patients received were female (91\%). The most common acne grade was grade II, followed by grades I, III, and IV, respectively (Figure 1).

The doctors could choose more than one type of treatment for each patient, and treatment choices varied according to acne severity (Table 1). Considering grade I acne, 94\% of Brazilian dermatologists chose topical treatment with drugs

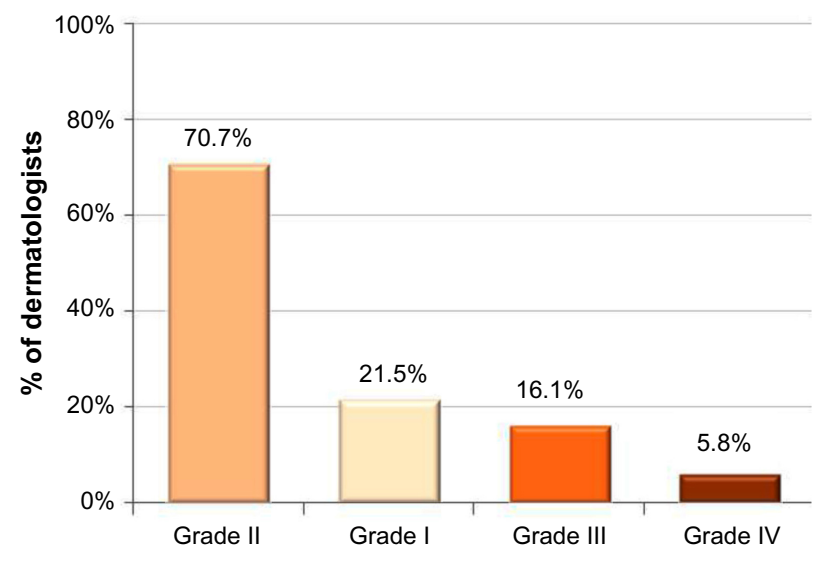

Figure I Most frequent acne grade received by dermatologists in clinic $(n=573)$. 
Table I Percentage of dermatologists choosing topical and/or oral medication options in relation to the acne grade of acne patients

\begin{tabular}{lllll}
\hline & Grade I & Grade II & Grade III & Grade IV \\
\hline $\begin{array}{l}\text { Topical treatment } \\
\text { with medication (yes) }\end{array}$ & $94 \%$ & $98 \%$ & $83 \%$ & $56 \%$ \\
$\begin{array}{l}\text { Systemic treatment } \\
\text { with medication (yes) }\end{array}$ & $28 \%$ & $64 \%$ & $96 \%$ & $98 \%$ \\
\hline
\end{tabular}

and for $76 \%$ of dermatologists at night-time), and only $28 \%$ of dermatologists chose systemic treatments (Table 1). The most frequently prescribed drugs are presented in Figure 2.

For grade II acne, the standard for treatment option for $98 \%$ of dermatologists was topical drugs mainly once daily, at night-time (Table 1). The choice for systemic drugs increased significantly compared to grade I acne; $64 \%$ of the dermatologists interviewed also chose an oral treatment for grade II acne patients (Table 1). The most frequently prescribed drugs are presented in Figure 3.

For grades III and IV acne, systemic treatment was the first option for $96 \%$ and $98 \%$ of dermatologists, respectively (Table 1). Interestingly, for grade III acne patients, $83 \%$ of dermatologists also considered a topical drug (in monotherapy or in association) and for grade IV only, 56\% of dermatologists considered a topical drug (Table 1). The most frequently prescribed drugs for grades III and IV are presented in Figures 4 and 5, respectively.

The prescription of dermocosmetics for acne patients is considered for all acne grades, but its prescription frequency

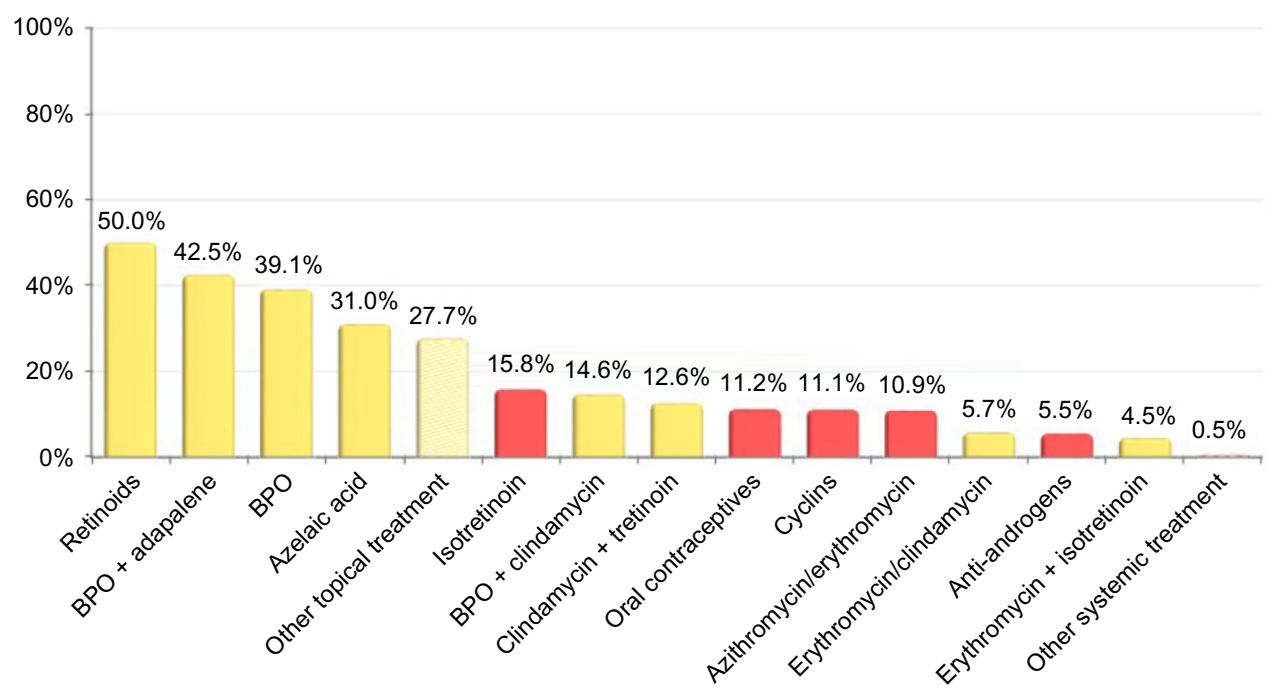

Figure 2 Percentage of dermatologists choosing each treatment choice for grade I acne patients ( $\mathrm{n}=596$ ).

Notes: Yellow bars, topical medication; red bars, systemic medication.

Abbreviation: BPO, benzoyl peroxide.

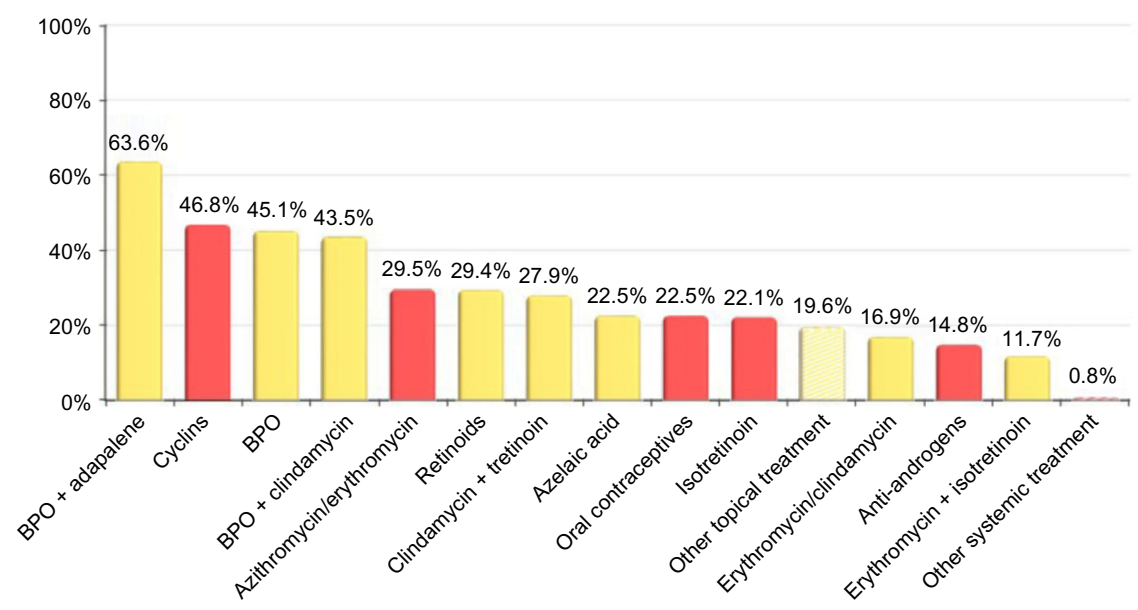

Figure 3 Percentage of dermatologists choosing each treatment choice for grade II acne patients ( $n=596$ ).

Notes: Yellow bars, topical medication; red bars, systemic medication.

Abbreviation: BPO, benzoyl peroxide. 


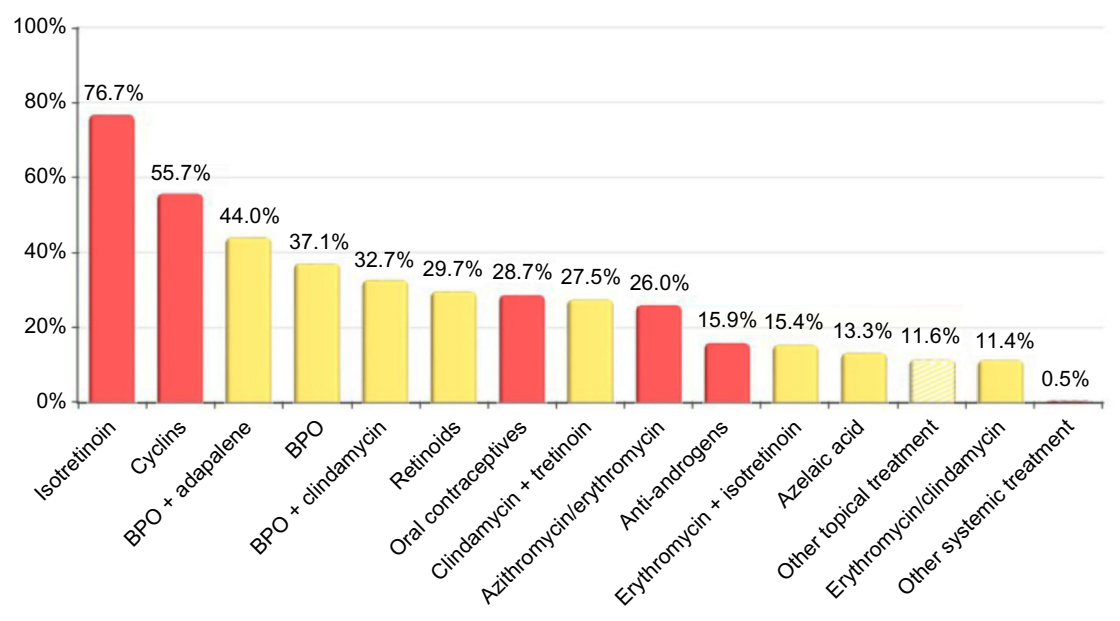

Figure 4 Percentage of dermatologists choosing each treatment choice for grade III acne patients $(n=596)$.

Notes: Yellow bars, topical medication; red bars, systemic medication.

Abbreviation: BPO, benzoyl peroxide.

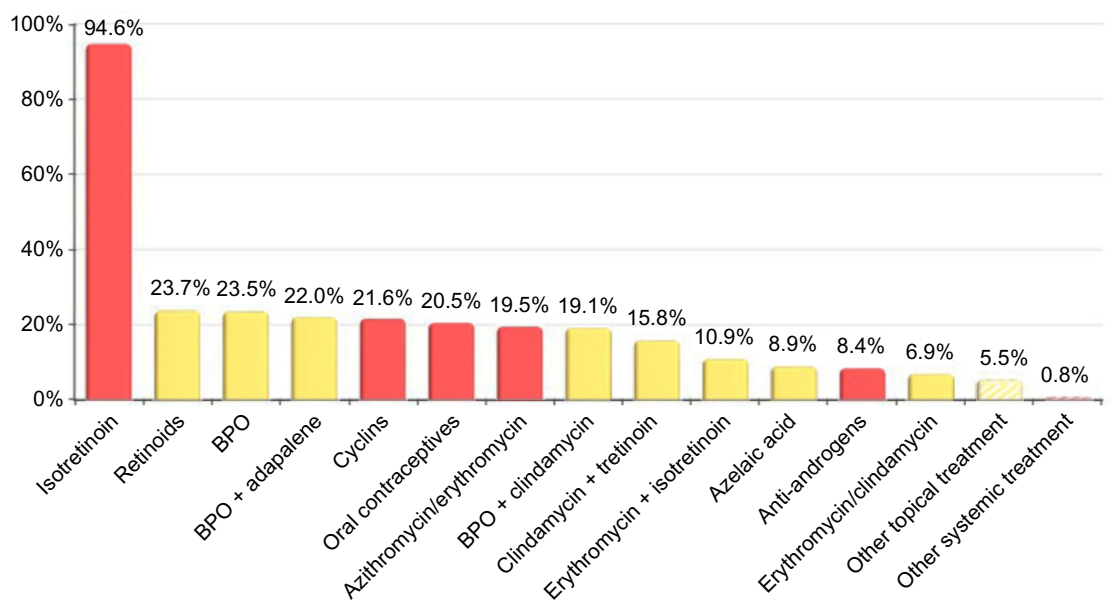

Figure 5 Percentage of dermatologist choosing each treatment choice for grade IV acne patients $(\mathrm{n}=596)$.

Notes: Yellow bars, topical medication; red bars, systemic medication.

Abbreviation: BPO, benzoyl peroxide.

decreases as acne severity increases (Table 2). Considering grade I acne, among the $75 \%$ of dermatologists prescribing dermocosmetics, $57 \%$ prescribe them only as adjunctive therapy and $20 \%$ only as maintenance therapy.

As described in Table 1,75\% of dermatologists answered that they prescribe a dermocosmetic for grade 1 acne. After that, they could choose more than one option; in adjunctive therapy, in maintenance therapy, and in monotherapy. For grades II, III, and IV acne, the use of dermocosmetics was considered by $67 \%, 56 \%$, and $44 \%$ of the surveyed dermatologists, respectively (Table 2). According to treatment option chosen (Table 1), the percentage of dermatologists prescribing dermocosmetics as adjunctive therapy with topical medication decreased from grade I to grade IV and was higher in adjunctive therapy with systemic medication than for topical ones (Table 2).
The choice of including a dermocosmetic in therapy has also varied largely from region to region: in São Paulo and in the South of Brazil, dermocosmetic use was higher than in Rio de Janeiro/Espírito Santo, Minas Gerais, and in the northern states of the country (Table 3).

\section{Discussion}

The present survey evaluated how 596 Brazilian dermatologists manage acne in private practice. Although the lack of validated measures was a limitation, the present survey provides a better understanding of how different grades of acne are being treated and how treatment is aligned with the standards established by international expert recommendations, such as from the Global Alliance Acne Treatment algorithm and the GILEA (Grupo Ibero-Latinoamericano de Estudio del Acné) algorithm (Figure 6). ${ }^{8,9,11,12}$ 
Table 2 Percentage of dermatologists choosing dermocosmetics in relation to the acne grade of acne patients

\begin{tabular}{|c|c|c|c|c|}
\hline & Grade I & Grade II & Grade III & Grade IV \\
\hline $\begin{array}{l}\text { Dermocosmetic(s) } \\
\text { (yes) }\end{array}$ & $75.0 \%$ & $67.3 \%$ & $55.7 \%$ & $44.1 \%$ \\
\hline Morning & $34.0 \%$ & $25.0 \%$ & $18.0 \%$ & $17.0 \%$ \\
\hline Evening & $31.0 \%$ & $20.0 \%$ & $16.0 \%$ & $15.0 \%$ \\
\hline $\begin{array}{l}\text { Average number of } \\
\text { applications per day }\end{array}$ & 1.65 & 1.68 & 1.74 & 1.79 \\
\hline $\begin{array}{l}\text { In adjunctive therapy } \\
\text { only (yes) }\end{array}$ & $56.8 \%$ & $65.8 \%$ & $69.3 \%$ & $70.9 \%$ \\
\hline $\begin{array}{l}\text { With topical } \\
\text { medication only }\end{array}$ & $73.7 \%$ & $70.6 \%$ & $58.2 \%$ & $61.9 \%$ \\
\hline $\begin{array}{l}\text { With systemic } \\
\text { medication only }\end{array}$ & $00.7 \%$ & $04.0 \%$ & $10.3 \%$ & $14.2 \%$ \\
\hline With both & $25.6 \%$ & $25.4 \%$ & $31.5 \%$ & $23.9 \%$ \\
\hline $\begin{array}{l}\text { In maintenance } \\
\text { therapy only (yes) }\end{array}$ & $20.0 \%$ & $16.8 \%$ & $14.7 \%$ & $11.7 \%$ \\
\hline $\begin{array}{l}\text { With topical } \\
\text { medication }\end{array}$ & $82.3 \%$ & $76.0 \%$ & $72.4 \%$ & $73.1 \%$ \\
\hline $\begin{array}{l}\text { With systemic } \\
\text { medication }\end{array}$ & $00.0 \%$ & $01.0 \%$ & $01.7 \%$ & $01.9 \%$ \\
\hline With both & $17.7 \%$ & $22.9 \%$ & $25.9 \%$ & $25.0 \%$ \\
\hline In monotherapy & $07.0 \%$ & $01.0 \%$ & $03.0 \%$ & $02.0 \%$ \\
\hline
\end{tabular}

Both the Global Alliance Acne Treatment and GILEA classify acne severity into mild, moderate, and severe categories, which differs from the present study classification in acne grades I, II, III, and IV (the Brazilian Society of Dermatology [SBD] classification). Therefore, to compare these study results with other acne treatment algorithms, we considered the equivalence measures described in Table 4.

In a previous study with 5,809 acne patients, it was observed that European dermatologists do not usually prescribe medical treatments to treat grade I acne (in $44 \%$ of cases, they prescribed only a dermocosmetic product to patients with very mild acne); one drug treatment, usually a topical one, to treat grade II acne (in $44 \%$ of cases, one treatment was prescribed to patients with mild acne); and two treatments (a combination of topical and systemic therapy) to those with grades III or IV acne. ${ }^{13}$

Topical medical treatment is recommended in both Global Alliance Acne Treatment algorithm and in the GILEA algo-

Table 3 Percentage of dermatologists choosing dermocosmetic prescription for grades I to IV acne, by region

\begin{tabular}{llllll}
\hline & SP (253) & RJ/ES (104) & MG (9I) & South (84) & Rest (64) \\
\hline Grade I & $85 \%$ & $77 \%$ & $59 \%$ & $86 \%$ & $67 \%$ \\
Grade II & $78 \%$ & $70 \%$ & $60 \%$ & $73 \%$ & $62 \%$ \\
Grade III & $64 \%$ & $50 \%$ & $52 \%$ & $63 \%$ & $45 \%$ \\
Grade IV & $47 \%$ & $52 \%$ & $47 \%$ & $55 \%$ & $23 \%$ \\
\hline
\end{tabular}

Abbreviations: SP, São Paulo; RJ, Rio de Janeiro; ES, Espírito Santo; MG, Minas Gerais. rithm as the first choice of prescription for grade 1 patients (topical retinoid or benzoyl peroxide [BPO], or BPO plus retinoid), and this recommendation is closer to actual Brazilian dermatologists practices as observed in the present survey (Figure 2). Although systemic drugs are not considered for patients with grade I acne in either the Global Alliance Acne Treatment or GILEA algorithms, $28 \%$ of Brazilian dermatologists also prescribed a systemic therapy (and 16\% of dermatologists use isotretinoin; Figure 2) for that population. This percentage increased significantly for grade II acne, when $64 \%$ of dermatologists chose a systemic treatment for their patients (and 22\% of dermatologists chose isotretinoin; Figure 3). For grades III and IV acne, systemic treatment became the first option for $96 \%$ and $98 \%$ of Brazilian dermatologists, respectively, which is in line with the literature. However, for them, the drug of choice for both grades of acne was isotretinoin (for $77 \%$ of dermatologists for grade III and for $95 \%$ of dermatologists for grade IV acne; Figures 4 and 5). Oral isotretinoin is a teratogenic drug, so its use is contraindicated in pregnant women and can be a first choice for grade IV or nodular/conglobate lesions in adolescents. Furthermore, it has been suggested that some patients may experience depression while using oral isotretinoin, but studies have not shown a decisive relationship. ${ }^{7,14,15}$

The development of bacterial resistance and ensuing recommendations from health authorities has limited the use of local and systematic antibiotics, favoring their use within the framework of combined therapy regimens. ${ }^{16,17}$ Nevertheless, in $12 \%$ of cases, only one local or systematic antibiotic has been noted to be prescribed by European dermatologists, which contradicts the published recommendations and indicates that dermatologists should not use antibiotics alone. ${ }^{13}$ Similarly, in our current survey,

Table 4 Acne severity classification according to the SBD, Global Alliance to Improve Outcomes in Acne, or GILEA

\begin{tabular}{|c|c|c|}
\hline SBD & $\begin{array}{l}\text { Global Alliance to Improve } \\
\text { Outcomes in Acne } \text { A }^{8,9}\end{array}$ & GILEA $^{11,12}$ \\
\hline Grade I & Mild - comedonal & Comedonal \\
\hline Grade II & $\begin{array}{l}\text { Mild - mixed and papular/pustular } \\
\text { Moderate - mixed and papular/ } \\
\text { pustular }\end{array}$ & $\begin{array}{l}\text { Papular/pustular mild } \\
\text { Papular/pustular } \\
\text { moderate }\end{array}$ \\
\hline Grade III & $\begin{array}{l}\text { Moderate - mixed and papular/ } \\
\text { pustular } \\
\text { Moderate - nodular } \\
\text { (with small nodules }<0.5 \mathrm{~cm} \text { ) }\end{array}$ & $\begin{array}{l}\text { Papular/pustular } \\
\text { severe } \\
\text { Nodular mild }\end{array}$ \\
\hline Grade IV & Severe - nodular/conglobate & $\begin{array}{l}\text { Nodular moderate } \\
\text { Nodular severe }\end{array}$ \\
\hline
\end{tabular}

Abbreviations: SBD, Brazilian Society of Dermatology; GILEA, Ibero Latin American Group of Study of Acne. 


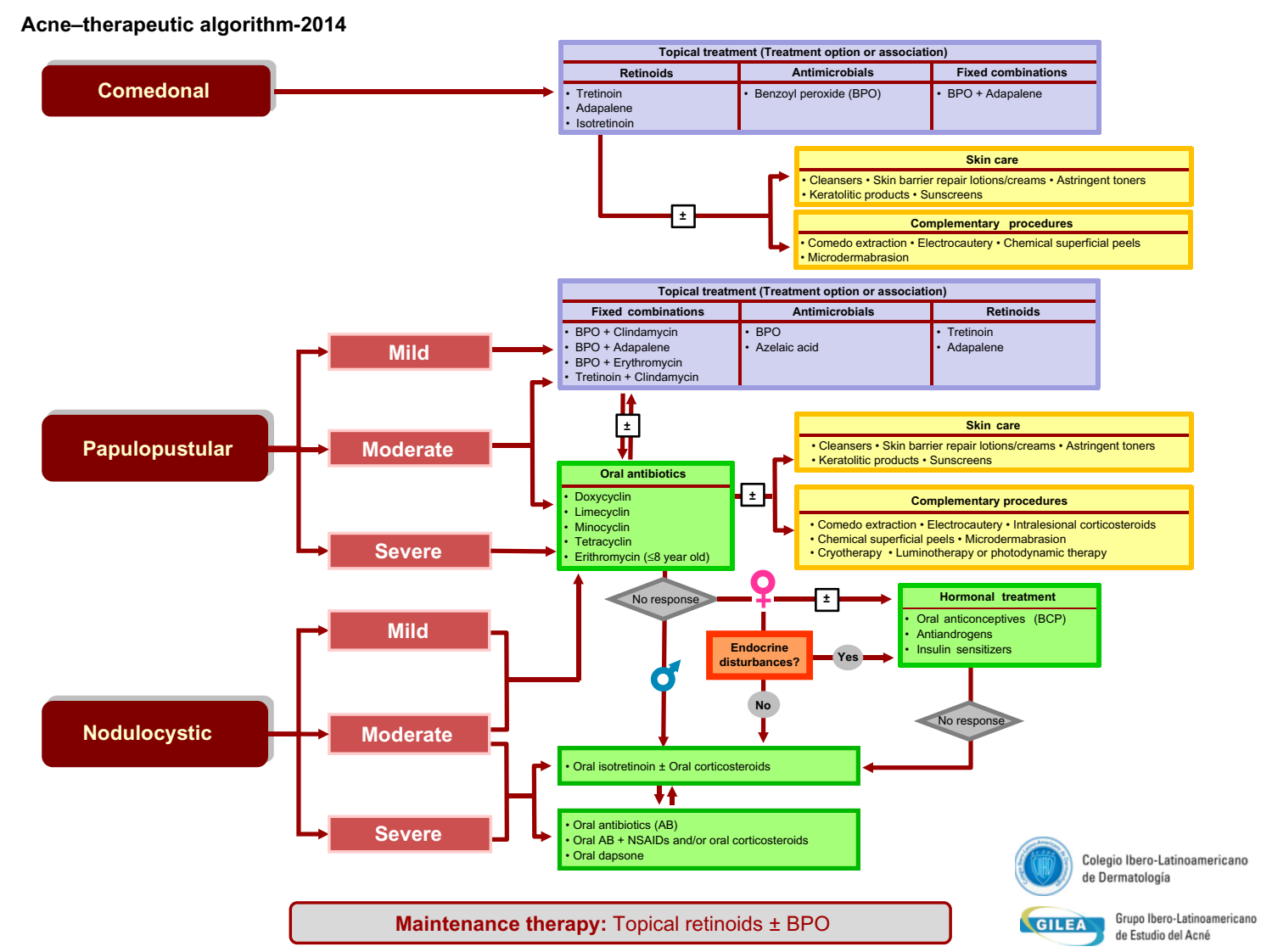

Figure 6 Acne therapeutic algorithm developed by GILEA during the CILAD 2014. Reproduced from Ibero Latina American Collage of Dermatology (CILAD). Available from: http://www.cilad.org/archivos/I/GILEA/alg_engl.pdf.'2

Abbreviations: NSAIDS, non-steroidal anti-inflammatories; BCP, birth control pills.

local and systematic antibiotics were heavily prescribed for all acne grades, either alone or in association, by Brazilian dermatologists (topical antibiotic was prescribed by $6 \%$ of dermatologists for grade I acne, by $17 \%$ for grade II acne, and by $11 \%$ and $7 \%$ of dermatologists for grades III and IV acne, respectively; oral antibiotic was prescribed by $11 \%$ of dermatologists for grade I acne, by $29 \%$ for grade II acne, and by $26 \%$ and $20 \%$ of dermatologists for grades III and IV acne, respectively). However, interestingly, Brazilian dermatologists favored topical and oral antibiotic use within the framework of combined therapy regimens, because for all grades of acne they frequently chose fixed combinations such as BPO plus adapalene, BPO plus clindamycin, or clindamycin plus tretinoin more than European dermatologists, perhaps because this recommendation is more clearly indicated in the GILEA algorithm (Figure 6).

The current survey data indicate an indiscriminate use of drugs by Brazilian dermatologists, particularly of isotretinoin, for mild to moderate acne, and highlights overuse of local and systematic antibiotics, practices that contradict the published recommendations and indicate that dermatologists should not use oral medication for mild to moderate acne or antibiotics alone in order to avoid bacterial resistance. These data also indicate that it is necessary to favor topical treatments with one application a day to ensure patients use the treatment regularly. $8,9,11,12$

Furthermore, only $7 \%$ of Brazilian dermatologists recommended dermocosmetics as monotherapy for grade I patients in the current survey, indicating the low consideration of active dermocosmetic treatment (ie, keratolytic products) for acne by Brazilian dermatologists, although dermocosmetics' effectiveness has been demonstrated, ${ }^{13}$ and they are recommended in both algorithms. . $^{8,911,12}$

Although the use of skin care products (cleanser, skin barrier repair, sunscreen, etc) is recommended in the GILEA algorithm in combination with drug therapy to improve patient tolerance of treatments and patient comfort while maintaining and/or strengthening the overall efficacy of the regimen, we noted in the current survey that a decreasing percentage of Brazilian dermatologists prescribed skin care products as the severity of acne increased (Table 2). Nevertheless, the prescription of skin care products in adjunc- 
tive therapy increased with the acne grade, particularly with the prescription of systemic medications well known for their secondary side effects (eg, skin dryness, irritation, photosensitization, etc). This result indicates that dermocosmetic products play an important role in acne treatment and should be considered by more dermatologists in future acne treatment protocols. Differences in dermocosmetic prescription practices between regions in Brazil were noted in the current survey, with a greater number of dermatologists prescribing dermocosmetics in the southern states compared to the northern ones (Table 3); this difference may be explained by climate differences (lower temperatures and humidity similar to European countries may explain the higher use of dermocosmetics in the southern states of Brazil).

\section{Conclusion}

In conclusion, the present survey shows that Brazilian dermatologists frequently prescribe several treatments for acne, a practice that diverges on many points from published recommendations, especially the Global Alliance Acne Treatment and GILEA algorithms. Furthermore, in spite of published recommendations contraindicating their use, isotretinoin plus local antibiotics, or systematic antibiotics alone, are often prescribed, even for mild/moderate acne. Finally, dermocosmetic products are rarely prescribed in monotherapy by Brazilian dermatologists in private practice, and should be considered in acne treatment protocols; unfortunately, these protocols have not yet been developed. In future, we propose the development of a Brazilian acne treatment algorithm to meet the specific needs of dermatologists in Brazil.

\section{Acknowledgments}

We would like to thank all the Brazilian dermatologists who participated in this survey. We would also like to thank Amy Whereat from Speak the Speech Consulting and Gene Colón, who provided editing assistance.

\section{Disclosure}

Sophie Seité and Clarice Caixeta are employed by La Roche-Posay Dermatological Laboratories, the sponsor of the study. The authors report no other conflicts of interest in this work.

\section{References}

1. Ramos-e-Silva M, Carneiro SC. Acne vulgaris: review and guidelines. Dermatol Nurs. 2009;21(2):63-68.

2. Thompson TT, Feldman SR, Fleischer AB Jr. Only 33\% of visits for skin disease in the US in 1995 were to dermatologists: is decreasing the number of dermatologists the appropriate response? Dermatol Online J. 1998;4(1):3.

3. Stern RS. Dermatologists and office-based care of dermatologic care in the 21st century. J Investig Dermatol Symp Proc. 2004;9(2): $126-130$.

4. Dréno B. Assessing quality of life in patients with acne vulgaris: implications for treatment. Am J Clin Dermatol. 2006;7:99-106.

5. Loney T, Standage M, Lewis S. Not just 'skin deep': psychosocial effects of dermatological-related social anxiety in a sample of acne patients. J Health Psychol. 2008;13:47-54.

6. Mallon E, Newton JN, Klassen A, Stewart-Brown SL, Ryan TJ, Finlay AY. The quality of life in acne: a comparison with general medical conditions using generic questionnaires. Br J Dermatol. 1999;140: 672-676.

7. Uhlenhake E, Yentzer BA, Feldman SR. Acne vulgaris and depression: a retrospective examination. J Cosmet Dermatol. 2010;9:59-63.

8. Gollnick H, Cunliffe W, Berson D, et al; Global Alliance to Improve Outcomes in Acne. Management of acne: a report from a Global Alliance to Improve Outcomes in Acne. J Am Acad Dermatol. 2003;49:S1-S37.

9. Dréno B, Thiboutot D, Gollnick H, et al; Global Alliance to Improve Outcomes in Acne. Large-scale worldwide observational study of adherence with acne therapy. Int J Dermatol. 2010;49:448-456.

10. Dall'oglio F, Tedeschi A, Fabbrocini G, Veraldi S, Picardo M, Micali G. Cosmetics for acne: indications and recommendations for an evidencebased approach. G Ital Dermatol Venereol. 2015;150(1):1-11.

11. Kaminsky A, Florez-White M, Arias MI, Bagatin E; en nombre del Grupo Ibero Latinoamericano de Estudio del Acné (GILEA-CILAD). Clasificación del acné: Consenso Ibero-Latinoamericano, 2014. Med Cutan Iber Lat Am. 2015;43(1):18-23.

12. ACNE - THERAPEUTIC ALGORITHM, from the Ibero Latin American Group of Study of Acne (GILEA): scientific group of the Ibero Latina American Collage of Dermatology (CILAD). Available from: http://www.cilad.org/archivos/1/GILEA/alg_eng1.pdf. Accessed November 28, 2014.

13. Seite S, Dréno B. A large-scale European observational study to describe the management of acne in clinical practice. In: Vega JP, editor. Advances in Dermatology Research. Hauppauge, NY: Nova Science Publishers; 2015:165-174.

14. Dréno B, Bettoli V, Ochsendorf F, et al. An expert view on the treatment of acne with systemic antibiotics and/or oral isotretinoin in the light of the new European recommendations. Eur J Dermatol. 2006;16(5): $565-571$.

15. Zouboulis CC, Bettoli V. Management of severe acne. Br J Dermatol. 2015;172:27-36.

16. Collignon PJ. Antibiotic resistance. Med J Aust. 2002;177(6): 325-329.

17. Kunynetz R. Systemic antibiotic therapy for acne: A review. Skin Therapy Lett. 2002;7(5):3-7.
Clinical, Cosmetic and Investigational Dermatology

\section{Publish your work in this journal}

Clinical, Cosmetic and Investigational Dermatology is an international, peer-reviewed, open access, online journal that focuses on the latest clinical and experimental research in all aspects of skin disease and cosmetic interventions. All areas of dermatology will be covered; contributions will be welcomed from all clinicians and

\section{Dovepress}

basic science researchers globally. This journal is indexed on CAS. The manuscript management system is completely online and includes a very quick and fair peer-review system, which is all easy to use. Visit http://www.dovepress.com/testimonials.php to read real quotes from published authors. 